\title{
Role of Adenosine Triphosphate (ATP) and NaK ATPase in the Inhibition of Proximal Tubule Transport with Intracellular Cystine Loading
}

\author{
Cynthia Coor, Richard F. Salmon, Raymond Quigley, Diana Marver, and Michel Baum \\ Departments of Pediatrics and Internal Medicine, University of Texas Southwestern Medical Center at Dallas
}

\begin{abstract}
Cellular cystine loading with cystine dimethyl ester inhibits volume absorption, transepithelial potential difference, glucose transport, and bicarbonate transport in proximal convoluted tubules perfused in vitro. This study examined the roles of ATP and NaK ATPase in this in vitro model of the Fanconi syndrome of cystinosis. Intracellular ATP was measured using the luciferin-luciferase assay. Intracellular ATP was reduced by $60 \%$ in proximal convoluted tubules incubated with $0.5 \mathrm{mM}$ cystine dimethyl ester for $15 \mathrm{~min}$ at $37^{\circ} \mathrm{C}(P<0.001)$. Incubation of cystine loaded tubules with $1 \mathrm{mM}$ exogenous ATP increased intracellular ATP to levels not significantly different than that of controls. On the other hand, Vmax NaK ATPase activity was unchanged even though the incubation times and the concentration of cystine dimethyl ester were doubled to 30 min and $1 \mathrm{mM}$, respectively. In proximal convoluted tubules perfused in vitro, $0.5 \mathrm{mM}$ cystine dimethyl ester resulted in an $89 \%$ inhibition in volume absorption $(0.81 \pm 0.14$ to $0.09 \pm 0.09$ $\mathrm{nl} / \mathrm{mm} \cdot \mathrm{min})$, while there was only a $45 \%$ inhibition in volume absorption $(P<0.01)$ due to cellular cystine loading in the presence of $1 \mathrm{mM}$ lumen and bath ATP $(0.94 \pm 0.05$ to $0.52 \pm 0.11 \mathrm{nl} / \mathrm{mm} \cdot \mathrm{min})$. These data demonstrate that proximal tubule cellular cystine loading decreases cellular ATP concentration, but does not directly inhibit $\mathrm{NaK}$ ATPase activity. The inhibition in transport and decrease in intracellular ATP due to cellular cystine loading was ameliorated by exogenous ATP. These data are consistent with cellular ATP depletion playing a major role in the inhibition of proximal tubule transport due to intracellular cystine loading. (J. Clin. Invest. 1991. 87:955-961.) Key words: cystinosis • Fanconi syndrome • cystine dimethyl ester $\bullet$ microperfusion
\end{abstract}

\section{Introduction}

Cystinosis is an autosomal recessive disorder characterized by a high concentration of the amino acid, cystine (1-3). The cystine accumulation occurs predominantly within lysosomes (26 ) where a defect in carrier-mediated efflux of cystine has been described (7-10). Insight into this defect was aided by the demonstration that lysosomes incubated with amino acid methyl esters cleave the methyl ester to form high concentrations of

Address correspondence and reprint requests to Dr. Michel Baum, Department of Pediatrics, University of Texas Southwestern Medical Center at Dallas, 5323 Harry Hines Boulevard, Dallas, TX 752359063.

Received for publication 8 May 1990 and in revised form 28 September 1990.

\section{J. Clin. Invest.}

(c) The American Society for Clinical Investigation, Inc.

0021-9738/91/03/0955/07 \$2.00

Volume 87, March 1991, 955-961 the less permeable amino acid $(11,12)$. Using this technique, cells can be incubated with cystine dimethyl ester to form high concentrations of intralysosomal cystine (8).

Cystinosis is the most common cause of the Fanconi syndrome in children (1). Incubation of tubule suspensions with cystine dimethyl ester results in high intracellular concentrations of cellular cystine comparable to that measured in kidney tissue from patients with cystinosis (13). We have recently shown that intracellular cystine loading using cystine dimethyl ester inhibits transport in the isolated perfused proximal convoluted tubule (14). In this in vitro model of the Fanconi syndrome of cystinosis, volume absorption, transepithelial potential difference, glucose transport, and bicarbonate transport were inhibited after the addition of $0.5 \mathrm{mM}$ bath cystine dimethyl ester. These parameters were not affected by the methyl esters of tryptophan or leucine. There was no change in the permeability of the proximal convoluted tubule to mannitol or bicarbonate after the addition of cystine dimethyl ester, indicating that the decrease in transport was not due to an alteration in membrane permeability, but rather to an inhibition of active transport.

The purposes of this study were to examine the role of intracellular ATP and NaK ATPase activity in this model of the Fanconi syndrome of cystinosis. Acute cystine loading of individual proximal convoluted tubules resulted in a decrease in intracellular ATP concentration, but did not alter $V_{\max } \mathrm{NaK}$ ATPase activity. The decrease in intracellular ATP returned to near control levels upon addition of exogenous ATP. In isolated perfused proximal convoluted tubules we confirmed that cellular cystine loading inhibits volume reabsorption. The inhibition in volume absorption in cystine-loaded tubules was attenuated by exogenous ATP.

\section{Methods}

Determination of ATP concentration in proximal convoluted tubules. Intracellular ATP concentration was measured using the protocol described by Uchida and Endou with minor modifications (15). Proximal convoluted tubules were dissected free hand from adult New Zealand White Rabbits in a cooled $\left(4^{\circ} \mathrm{C}\right)$ modified Hanks' solution containing $137 \mathrm{mM} \mathrm{NaCl}, 5 \mathrm{mM} \mathrm{KCl}, 0.8 \mathrm{mM} \mathrm{MgSO}_{4}, 0.33 \mathrm{mM} \mathrm{Na}_{2} \mathrm{HPO}_{4}, 0.44$ $\mathrm{mM} \mathrm{KH} \mathrm{PO}_{4}, 1 \mathrm{mM} \mathrm{MgCl}, 10 \mathrm{mM}$ Tris- $\mathrm{HCl}, 0.25 \mathrm{mM} \mathrm{CaCl}, 2 \mathrm{mM}$ glutamine, and $2 \mathrm{mM}$ L-lactate. This solution was bubbled with $100 \%$ $\mathrm{O}_{2}$ and had a $\mathrm{pH}$ of 7.4 (15). The proximal convoluted tubules were measured using an ocular micrometer, and then transferred in $2 \mu \mathrm{l}$ of dissection medium into a $5-\mu 1$ well of a chilled microplate (Sarstedt, Rommelsdorf, Germany). In all tubule incubation studies the dissector (M.B.) was blinded as to the experimental group to which the tubule would be included. In addition, each series of experiments contained approximately the same number of tubules from each rabbit in each experimental condition studied. $1 \mu \mathrm{l}$ of chilled Hanks' solution was added to each well containing control tubules. $1 \mu \mathrm{l}$ of Hanks' solution containing $1.5 \mathrm{mM} \mathrm{L}$-cystine dimethyl ester was added to the wells in the experimental group to give a final concentration of $0.5 \mathrm{mM}$ cystine dimethyl ester. The samples were gently shaken for $60 \mathrm{~s}$. Filter paper 
moistened with distilled water was placed around the inside wall of the plates to prevent evaporation and the plates were covered. The plates were then placed on top of sand within a water bath at $37^{\circ} \mathrm{C}$ for $15 \mathrm{~min}$.

Immediately after incubation $2 \mu \mathrm{l}$ of $12.5 \%$ trichloroacetic acid containing $5 \mathrm{mM}$ EDTA was added to each well and the plates vibrated for 5 min with a titer plate shaker (Lab Line Instruments, Melrose Park, IL) to extract the intracellular ATP. The sample was transferred to a cuvette filled with $400 \mu \mathrm{l}$ of $0.1 \mathrm{M}$ Tris/acetate buffer containing 0.5 mM EDTA (pH 7.7). The ATP content was determined using the firefly luciferin/luciferase assay previously described $(15,16)$. The cuvette containing the sample was placed in the sample port of the luminometer (LKB 1250; LKB Instruments, Inc., Gaithersburg, MD). $100 \mu \mathrm{l}$ of ATP monitoring reagent (LKB 1243-200) was added manually into the injection chamber. The peak light intensity was measured after injection using a chart recorder. ATP concentration was calculated from a standard curve that was linear from $10^{-14}$ to $10^{-11} \mathrm{~mol} \mathrm{ATP} /$ tube $(r$ $=0.993) .0 .5 \mathrm{mM}$ cystine dimethyl ester had no effect on the standard curve.

In experiments designed to examine the effect of exogenous ATP on the intracellular ATP concentration, $\mathrm{Na}_{2}$ ATP was added to Hanks' solution to yield a final concentration of $1 \mathrm{mM}$ ATP before a 15-min incubation at $37^{\circ} \mathrm{C}$. Four conditions were studied simultaneously: control, control + $1 \mathrm{mM}$ ATP, experimental containing $0.5 \mathrm{mM}$ cystine dimethyl ester, and experimental with $0.5 \mathrm{mM}$ cystine dimethyl ester plus $1 \mathrm{mM}$ ATP. Immediately after incubation, tubules were transferred using a pipette and washed in wells containing $15 \mu \mathrm{l}$ of chilled Hanks' solution $\times 2$ before placement in a well containing $3 \mu \mathrm{l}$ of Hanks' solution and $2 \mu \mathrm{l}$ of $12.5 \%$ trichloroacetic acid. The measurement of intracellular ATP was performed as described above.

[Methoxy $-{ }^{3} \mathrm{H}$ ] inulin was used as a marker in a series of experiments $(n=9)$ to determine the amount of exogenous ATP that might be carried with the tubules. Only $1.2 \pm 0.3 \times 10^{-14} \mathrm{~mol}$ of ATP per tubule would be measured as the result of contamination with exogenous ATP.

Determination of $\mathrm{NaK}$ and $\mathrm{Mg}$ ATPase activity in proximal convoluted tubules. NaK ATPase activity was measured by a modification of the microfluorometric assay of O'Neil and Dubinsky (17). Individual proximal convoluted tubules were dissected and their lengths determined as described above. Tubules were transferred in $2 \mu \mathrm{l}$ of dissection medium to individual $1.5 \mathrm{ml}$ snap-capped microcentrifuge tubes. Then $2 \mu$ l of chilled Hanks' solution with or without cystine dimethyl ester ( $1.0 \mathrm{mM}$ final concentration) was added to each sample. The droplets were coalesced by a brief switch on and off of a Beckman microfuge (Beckman Instruments, Inc., Palo Alto, CA) followed by incubation of the samples in a water bath for $30 \mathrm{~min}$ at $37^{\circ} \mathrm{C}$. Immediately postincubation, $4 \mu \mathrm{l}$ of ice-cold distilled water was added to each tube and the samples freeze-thawed for a total of three times to disrupt tubular membranes.

An ATPase assay medium containing $60 \mathrm{mM} \mathrm{NaCl}, 60 \mathrm{mM}$ choline $\mathrm{Cl}, 30 \mathrm{mM} \mathrm{KCl}, 5 \mathrm{mM}$ vanadate-free $\mathrm{Na}_{2}$ ATP, $5 \mathrm{mM} \mathrm{MgCl}, 1$ $\mathrm{mM}$ ascorbic acid, $1 \mathrm{mM}$ EDTA, $10 \mathrm{mM}$ phosphoenolpyruvate, $1 \mathrm{mM}$ $\mathrm{NADH}, 5 \mu \mathrm{g} / \mathrm{ml}$ pyruvate kinase, $5 \mathrm{U} / \mathrm{ml}$ lactate dehydrogenase, low fluorescence blank imidazole buffer $(50 \mathrm{mM}, \mathrm{pH} 7.0)$, and \pm ouabain $(1.5 \mathrm{mM})$ were then used to initiate the ATPase reaction. Some experiments were performed where, in addition to ouabain, either $10 \mu \mathrm{g} / \mathrm{ml}$ oligomycin, $1 \mathrm{mM} N$-ethylmaleimide (NEM), ${ }^{1}$ or $0.5 \mathrm{mM}$ Na-orthovanadate were added. The final assay volume was $24 \mu \mathrm{l}$. Assay blanks as well as ADP standards (500-4,000 pmol/tube) were included among the samples. Standard curves were carried out not only with ATPase assay media with or without added ouabain (or the other inhibitors examined), but with or without added cystine dimethyl ester at the concentration present in the tissue samples. This was necessary as ouabain, cystine dimethyl ester, and other inhibitors employed were found to have small but perceptible effects on the final fluorescence obtained with the standards.

1. Abbreviations used in this paper: $J_{\mathrm{v}}$, volume absorption; NEM, $N$ ethylmaleimide.
After a 30 -min incubation at $37^{\circ} \mathrm{C}$ of blanks, ADP standards, and tubules, the assay was stopped by the addition of $24 \mu \mathrm{l}$ of $0.5 \mathrm{~N} \mathrm{HCl}$ and placing the tubes briefly on ice. To ensure adequate mixing of the acid and the samples, the tubes were centrifuged for $30 \mathrm{~s}$ on the Beckman microfuge followed by a 20 -min incubation at room temperature to allow for the acid destruction of residual NADH. To convert the NAD to a fluorescent product, $270 \mu \mathrm{l}$ of $6 \mathrm{~N} \mathrm{NaOH}$ was added to each tube under reduced lighting conditions. The tubes were vortexed vigorously and placed into a $60^{\circ} \mathrm{C}$ water bath for $20 \mathrm{~min}$. After incubation, a $730-\mu l$ aliquot of ice-cold distilled water was pipetted into each sample. When the samples reached room temperature, fluorescence was monitored using a Zeiss PMQ III spectrophotometer-fluorometer (Oberkochen, FRG) using a 340-nm excitation light source and a 460-nm emission filter. ATPase activity is reported as pmol ADP formed $/ \mathrm{mm}$ tubule $\cdot h$. NaK ATPase activity was determined as the difference between the total ATPase and ouabain-insensitive, or $\mathrm{Mg}$ ATPase activity.

In vitro microperfusion. Proximal convoluted tubules were perfused as previously described $(14,18,19)$. Briefly, midcortical and juxtamedullary proximal convoluted tubules were dissected in a cooled $\left(4^{\circ} \mathrm{C}\right)$ ultrafiltrate-like solution containing $115 \mathrm{mM} \mathrm{NaCl}, 25 \mathrm{mM}$ $\mathrm{NaHCO}_{3}, 2.3 \mathrm{mM} \mathrm{Na} \mathrm{HPO}_{4}, 10 \mathrm{mM} \mathrm{Na}$ acetate, $1.8 \mathrm{mM} \mathrm{CaCl}_{2}, 1$ $\mathrm{mM} \mathrm{MgSO}_{4}, 5 \mathrm{mM} \mathrm{KCl}, 8.3 \mathrm{mM}$ glucose, and $5 \mathrm{mM}$ alanine. Tubules were transferred to a $1.2-\mathrm{ml}$ temperature controlled bath $\left(38^{\circ} \mathrm{C}\right)$ and perfused at $\sim 10 \mathrm{nl} / \mathrm{min}$ with the above ultrafiltrate-like solution using concentric glass pipettes. The tubules were bathed with a similar solution containing $6 \mathrm{~g} / \mathrm{dl}$ bovine serum albumin. All solutions were bubbled with $95 \% \mathrm{O}_{2}$ and $5 \% \mathrm{CO}_{2}$ at $37^{\circ} \mathrm{C}$ and had a pH of 7.4. The osmolality of the bathing solution and perfusate were adjusted to 290 mosmol/ $\mathrm{kg} \mathrm{H}_{2} \mathrm{O}$ by the addition of either $\mathrm{NaCl}$ or $\mathrm{H}_{2} \mathrm{O}$. The $\mathrm{pH}$ and osmolality of the bathing solution were maintained by continuously changing the bath at a rate of $0.5 \mathrm{ml} / \mathrm{min}$.

The first period began after a 45-min equilibration period. Volume absorption $\left(J_{\mathrm{v}}\right.$; in $\left.\mathrm{nl} \cdot \mathrm{mm}^{-1} \cdot \mathrm{min}^{-1}\right)$ was determined as the difference between the perfusion and collection rates $(\mathrm{nl} / \mathrm{min})$ normalized per millimeter of tubular length. Exhaustively dialyzed [methoxy $-{ }^{3} \mathrm{H}$ ]inulin was added to the perfusate as a marker of volume absorption at a concentration of $50 \mu \mathrm{Ci} / \mathrm{ml}$. The collection rate was measured using a $50-60 \mathrm{nl}$ constant volume pipette. The length of the tubule was measured using an eyepiece micrometer.

The first microperfusion protocol examined the effect of $0.1 \mathrm{mM}$, $0.25 \mathrm{mM}$, and $0.5 \mathrm{mM}$ cystine dimethyl ester on volume absorption in the proximal convoluted tubule. After a 15-min incubation period, cystine dimethyl ester was added to the bathing solution and four collections for volume absorption were performed.

The next microperfusion protocols were designed to examine if exogenous ATP affected volume reabsorption in proximal convoluted tubules. In the first study, tubules were perfused with an ultrafiltratelike solution and bathed in a serum-like albumin solution. After the control period, the bath and luminal solutions were exchanged with solutions that were identical to the control period to serve as a time control. In the next series of experiments, tubules were perfused with an ultrafiltrate-like solution and bathed with a serum-like albumin solution in the control period. In the experimental period, $1 \mathrm{mM}$ ATP was added to the bathing solution and luminal perfusate.

To determine if exogenous ATP affects the inhibition in transport seen after intracellular cystine loading, tubules were perfused with an ultrafiltrate-like solution and bathed in a serum-like albumin solution. Cystine dimethyl ester $(0.5 \mathrm{mM})$ was added to the bath after the control period. After a 15-min equilibration period, four collections for measurement of $J_{v}$ were performed. The next set of tubules were perfused and bathed in similar solutions except that $1 \mathrm{mM}$ ATP was present in both the bath and perfusate. After the control period, $0.5 \mathrm{mM}$ cystine dimethyl ester was added to the bath. An equilibration period of $10 \mathrm{~min}$ preceded four timed collections to measure the effect of ATP on $J_{v}$ in the presence of $0.5 \mathrm{mM}$ cystine dimethyl ester.

There were at least three measurements of each parameter in a given period for each tubule. The mean values for individual periods in 


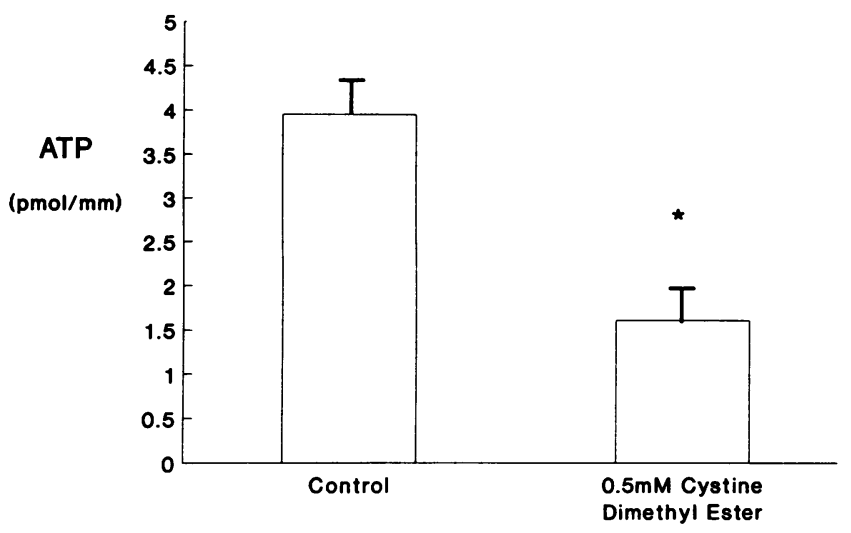

Figure 1. Effect of $0.5 \mathrm{mM}$ cystine dimethyl ester on intracellular proximal convoluted tubule ATP concentration. ${ }^{*} P<0.001$.

a given tubule were used to calculate the mean value for that period. Data are expressed as a mean \pm SEM. The Student's $t$ test for paired and unpaired data was used to determine statistical significance.

\section{Results}

The first series of experiments measured intracellular ATP concentration in nonperfused proximal convoluted tubules incubated with $(n=13)$ and without $(n=13)$ cystine dimethyl ester. The results are shown in Fig. 1. The mean tubular length of tubules incubated with and without cystine dimethyl ester was $0.91 \pm 0.06$ and $0.88 \pm 0.06 \mathrm{~mm}$, respectively. Intracellular ATP was $3.9 \pm 0.4 \times 10^{-12} \mathrm{~mol}$ of ATP $/ \mathrm{mm}$ in control tubules and $1.6 \pm 0.4 \times 10^{-12} \mathrm{~mol}$ of $\mathrm{ATP} / \mathrm{mm}$ in tubules incubated with cystine dimethyl ester for $15 \mathrm{~min}(P<0.001)$. Thus, intracellular cystine loading results in a significant decrease in intracellular ATP concentration.

In a second series of experiments, we examined if exogenous ATP could affect the intracellular ATP concentration. Four groups of tubules were simultaneously examined: control, experimental with $0.5 \mathrm{mM}$ cystine dimethyl ester, control plus $1 \mathrm{mM}$ ATP, and experimental with $0.5 \mathrm{mM}$ cystine dimethyl ester plus $1 \mathrm{mM}$ ATP. The mean tubular length was $0.61 \pm 0.03 \mathrm{~mm}$. The results are shown in Fig. 2. The intracellular ATP concentration in control tubules was $2.3 \pm 0.5 \times 10^{-12}$ $\mathrm{mol} / \mathrm{mm}(n=12)^{2}$ and $0.3 \pm 0.1 \times 10^{-12} \mathrm{~mol} / \mathrm{mM}(n=11)$ in tubules incubated with $0.5 \mathrm{mM}$ cystine dimethyl ester $(P$ $<0.001)$. Incubation of tubules $(n=13)$ with $1 \mathrm{mM}$ exogenous ATP resulted in an increase in intracellular ATP to $3.3 \pm 0.3$ $\times 10^{-12} \mathrm{~mol} / \mathrm{mm}(0.05<P<0.1)$ compared with controls incubated without exogenous ATP. Importantly, incubation of cystine loaded tubules with exogenous ATP resulted in an increase in intracellular ATP to $1.9 \pm 0.5 \times 10^{-12} \mathrm{~mol} / \mathrm{mm}(n=$ 14 ), a value not different than $2.3 \pm 0.5 \times 10^{12} \mathrm{~mol} / \mathrm{mm}$ measured in controls $(P>0.5)$.

2. The control ATP concentration in this group was significantly lower than that measured in the first series shown in Fig. 1. To examine if this was due to washing of the tubules in the second group of experiments, we measured intracellular ATP using the same group of rabbits with and without washing. Intracellular ATP was $2.8 \pm 0.4 \times 10^{-12} \mathrm{~mol} / \mathrm{mm}$ in unwashed tubules $(n=14)$ and $2.2 \pm 0.3$ in washed tubules $(n=18), P$ $>0.3$. Thus, while washing may result in a small decrease in intracellular ATP, the rabbit to rabbit variability appears to be the greater factor.

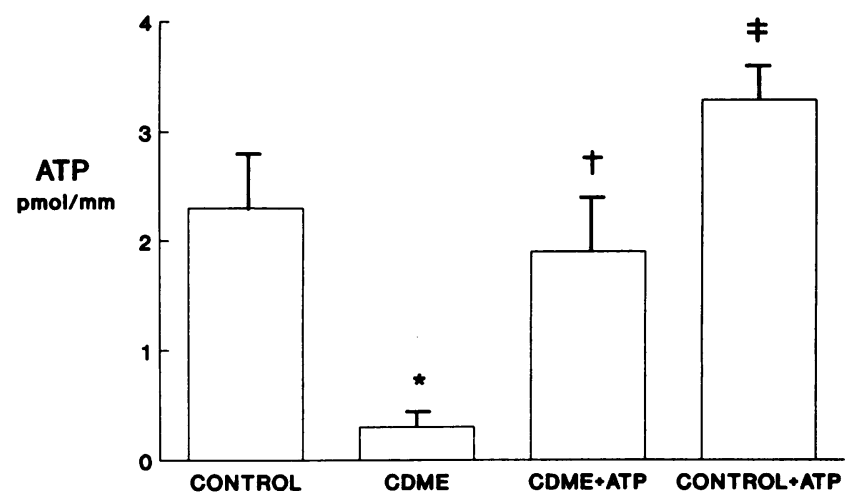

Figure 2. Effect of exogenous ATP on intracellular proximal convoluted tubule ATP concentration. ${ }^{*} P<0.01$ vs. control, and CDME + ATP, and control + ATP. ${ }^{\dagger}$ Not different than controls $(P$ $>0.5$ ). ${ }^{\ddagger} P<0.05$ vs. CDME and CDME + ATP, $0.05<P<0.10$ vs. controls.

The third series of experiments measured NaK ATPase activity in proximal convoluted tubules with and without $1 \mathrm{mM}$ cystine dimethyl ester. The mean tubular length was $0.71 \pm 0.02$ $\mathrm{mm}$. The results are shown in Fig. 3. Under $V_{\max }$ conditions, total ATPase activity was $8165 \pm 378 \mathrm{pmol}$ ADP generated/ $\mathrm{mm} \cdot \mathrm{h}$ in controls $(n=33)$ and $7413 \pm 354 \mathrm{pmol} / \mathrm{mm} \cdot \mathrm{h}$ in tubules incubated with cystine dimethyl ester $(n=28)$. Interestingly, there was a small but significant decrease in ouabain-insensitive ATPase activity in tubules incubated with cystine dimethyl ester. Mg ATPase activity was $3955 \pm 235 \mathrm{pmol} / \mathrm{mm} \cdot \mathrm{h}$ $(n=20)$ in the control group and $3006 \pm 192 \mathrm{pmol} / \mathrm{mm} \cdot \mathrm{h}(n$ $=31)$ in the group incubated with cystine dimethyl ester $(P$ $<0.005$ ). However, the derived NaK ATPase activities were not different. The activity in control tubules was $4210 \pm 510$ and $4407 \pm 393 \mathrm{pmol} / \mathrm{mm} \cdot \mathrm{h}$ in the tubules incubated with cystine dimethyl ester. Thus, under optimal concentrations of substrates, cellular cystine loading has no effect on NaK ATPase activity.

While the above studies demonstrate that cystine loading has no effect on $V_{\max } \mathrm{NaK}$ ATPase, there was a decrease in the ouabain-insensitive ATPase. In the next series of experiments we examined the effect of oligomycin (20), $N$-ethylmaleimide

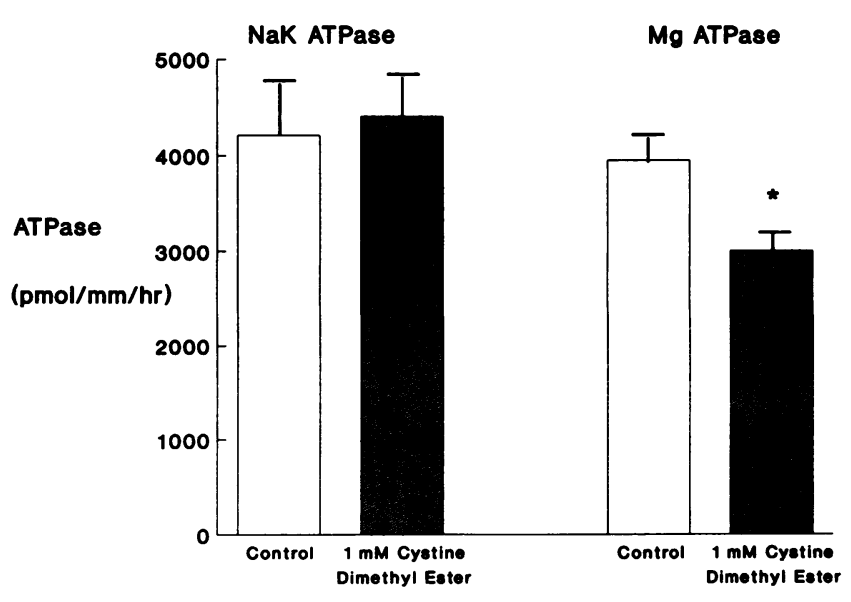

Figure 3. Effect of $1.0 \mathrm{mM}$ cystine dimethyl ester on NaK ATPase and $\mathrm{Mg}$ ATPase in proximal convoluted tubules. ${ }^{*} P<0.005$. 
Table I. Effect of Oligomycin, N-Ethylmaleimide and Vanadate on Ouabain-insensitive ATPase Activity in Control and Cystine Loaded Tubules

\begin{tabular}{lcccccc}
\hline & \multicolumn{2}{c}{ Control } & & \multicolumn{2}{c}{$1 \mathrm{mM}$ CDME } \\
\cline { 3 - 5 } \multicolumn{1}{c}{ Inhibitor } & $n$ & $p$ mol ADP/mm/h & $n$ & pmol ADP/mm/h & $P$ value \\
\hline Oligomycin $(10 \mu \mathrm{g} / \mathrm{ml})$ & 29 & $2316 \pm 232$ & 31 & $383 \pm 222$ & $<0.001$ \\
$N$-ethylmaleimide $(1 \mathrm{mM})$ & 19 & $3033 \pm 322$ & 18 & $1314 \pm 307$ & $<0.001$ \\
Vanadate $(0.5 \mathrm{mM})$ & 16 & $4301 \pm 438$ & 17 & $2846 \pm 387$ & $<0.01$ \\
\hline
\end{tabular}

(21), and sodium orthovanadate (20) on ouabain-insensitive ATPase activity. The mean tubular length was $0.72 \pm 0.02$. The results are shown in Table I. As can be seen, a significant difference between residual $\mathrm{Mg}$ ATPase activities persisted in the three groups between the control and the cystine loaded tubules.

The first in vitro microperfusion experiments were time controls where the luminal and bath solutions were exchanged with the same solutions used in the control period. These results are shown in Fig. $4 \mathrm{~A}$. The mean tubular length was $1.7 \pm 0.1 \mathrm{~mm}(n=14)$. The perfusion rate was $11.07 \pm 0.24$ and $10.99 \pm 0.20 \mathrm{nl} / \mathrm{min}$ in the control period, and after the fluid exchanges, respectively $(P=\mathrm{NS})$. $J_{\mathrm{v}}$ was $0.71 \pm 0.07$ in the control period and $0.73 \pm 0.08 \mathrm{nl} \cdot \mathrm{mm}^{-1} \cdot \min ^{-1}$ after the fluid exchanges $(P=\mathrm{NS})$.

The second series of in vitro microperfusion experiments was designed to examine the effect of exogenous ATP on volume absorption in the proximal convoluted tubule. The effect of the addition of $1 \mathrm{mM}$ ATP to the luminal and bathing solution is shown in Fig. $4 \mathrm{~B}$. The mean tubular length was $1.7 \pm 0.1$ $\mathrm{mm}(n=12)$. The perfusion rate in the control period was $10.96 \pm 0.21$ and $11.36 \pm 0.22 \mathrm{nl} / \mathrm{min}$ after the addition of $1 \mathrm{mM}$
A.

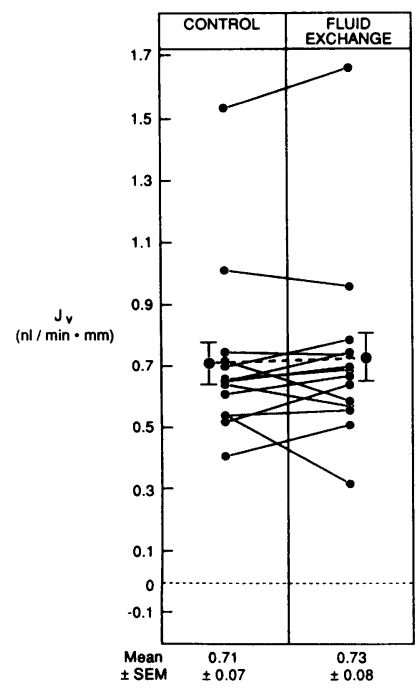

B.

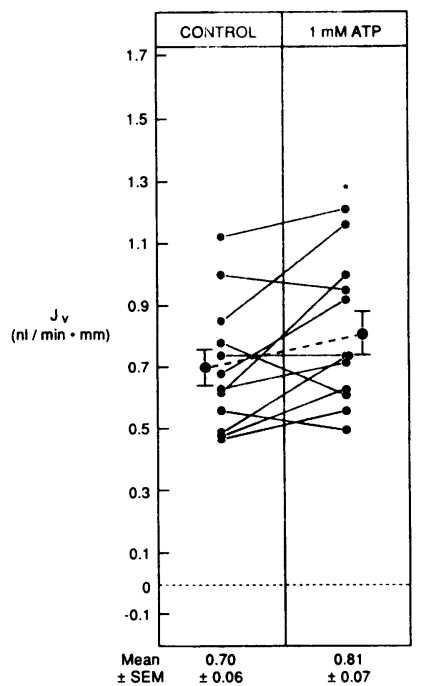

Figure 4. (A) Time control examining the effect of a luminal and bath change on volume absorption $\left(J_{\mathrm{v}}\right)$ in proximal convoluted tubules. $(B)$ Effect of exogenous $1 \mathrm{mM}$ lumen and bath ATP on volume absorption in proximal convoluted tubules. ${ }^{*} P<0.05$.
ATP to the bathing solution and perfusate. $J_{\mathrm{v}}$ in the control period was $0.70 \pm 0.06$ and $0.81 \pm 0.07 \mathrm{nl} \cdot \mathrm{mm}^{-1} \cdot \mathrm{min}^{-1}$ after the addition of $1 \mathrm{mM}$ ATP $(P=0.04)$. Thus, exogenous ATP resulted in a small but significant increase in volume absorption when evaluated in a paired fashion.

The next two series of experiments were performed to determine if exogenous ATP affects the inhibition in transport seen after the addition of $0.5 \mathrm{mM}$ cystine dimethyl ester. 0.5 $\mathrm{mM}$ cystine dimethyl ester was employed because previous studies have demonstrated a significant fall in volume absorption with no affect on mannitol or bicarbonate permeability (14). A dose response of the affect of cystine dimethyl ester is shown in Table II. In tubules examining the effect of $0.5 \mathrm{mM}$ cystine dimethyl ester, the perfusion rate was $11.35 \pm 0.53$ and $10.99 \pm 0.32 \mathrm{nl} / \mathrm{min}$ in the control period and experimental period, respectively. $J_{\mathrm{v}}$ was $0.81 \pm 0.14$ in the control period and fell significantly to $0.09 \pm 0.09 \mathrm{nl} \cdot \mathrm{mm}^{-1} \cdot \mathrm{min}^{-1}$ after the addition of $0.5 \mathrm{mM}$ cystine dimethyl ester $(P<0.001)$ as seen in Fig. $5 A$, Table II.

In the next series of experiments proximal convoluted tubules were perfused and bathed with the same solutions as above except that they contained $1 \mathrm{mM}$ ATP. In the experimental period $0.5 \mathrm{mM}$ cystine dimethyl ester was added to the bathing solution. The mean tubular length was $1.7 \pm 0.1 \mathrm{~mm}(n$
A.

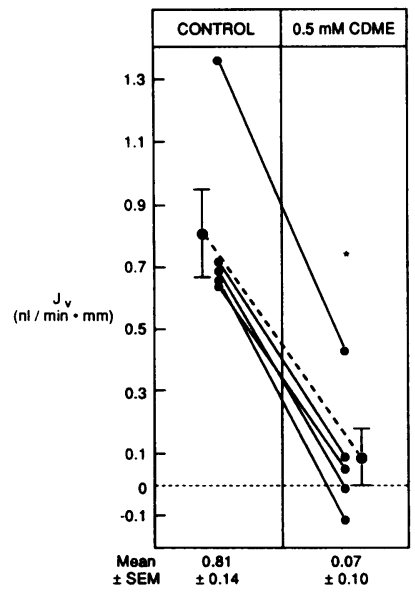

B.

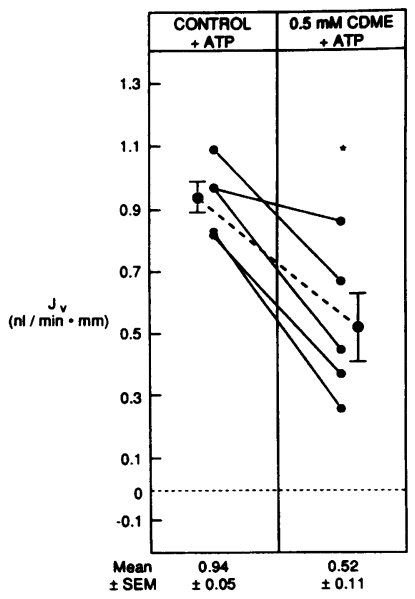

Figure 5. $(A)$ Effect of $0.5 \mathrm{mM}$ cystine dimethyl ester on volume absorption in proximal convoluted tubules. ${ }^{*} P<0.001$. (B) Effect of $0.5 \mathrm{mM}$ cystine dimethyl ester on volume absorption in proximal convoluted tubules in the presence of $1 \mathrm{mM}$ lumen and bath ATP. ${ }^{*} P<0.01 ; P=0.08$ vs. control. 


\begin{tabular}{|c|c|c|c|c|c|c|c|}
\hline \multirow[b]{2}{*}{ Dose } & \multirow[b]{2}{*}{$n$} & \multirow[b]{2}{*}{1} & \multicolumn{2}{|c|}{ Control } & \multicolumn{2}{|c|}{ CDME } & \multirow[b]{2}{*}{$P$ value } \\
\hline & & & Vo & $J v$ & Vo & $J v$ & \\
\hline $0.1 \mathrm{mM}$ & 4 & $1.2 \pm 0.3$ & $11.69 \pm 0.37$ & $0.76 \pm 0.15$ & $11.60 \pm 0.31$ & $0.76 \pm 0.11$ & NS \\
\hline $0.25 \mathrm{mM}$ & 9 & $1.4 \pm 0.1$ & $11.42 \pm 0.14$ & $0.59 \pm 0.06$ & $11.52 \pm 0.25$ & $0.44 \pm 0.08$ & $<0.05$ \\
\hline $0.5 \mathrm{mM}$ & 5 & $1.5 \pm 0.2$ & $11.35 \pm 0.53$ & $0.81 \pm 0.14$ & $10.99 \pm 0.32$ & $0.09 \pm 0.09$ & $<0.001$ \\
\hline
\end{tabular}

$=5)$. The perfusion rate in the control period was $12.06 \pm 0.13$ and $12.18 \pm 0.21 \mathrm{nl} / \mathrm{min}$ after the addition of $0.5 \mathrm{mM}$ cystine dimethyl ester. $J_{\mathrm{v}}$ in the control period ( $1 \mathrm{mM}$ ATP in the bath and perfusate) was $0.94 \pm 0.05$ and fell to $0.52 \pm 0.11$ $\mathrm{nl} \cdot \mathrm{mm}^{-1} \cdot \mathrm{min}^{-1}$ after the addition of cystine dimethyl ester to the bathing solution $(P<0.01)$ as shown in Fig. $5 B$. Thus, addition of cystine dimethyl ester resulted in a fall in volume absorption to $11 \%$ of control compared with $55 \%$ of control in the presence of ATP $(P<0.01)$. These data demonstrate that exogenous ATP attenuates the fall in transport seen after the addition of cystine dimethyl ester.

\section{Discussion}

We have recently demonstrated that cellular cystine loading inhibits active transport in proximal convoluted tubules perfused in vitro (14). This study examined the role of intracellular ATP and NaK ATPase in the transport defect observed in cystine loaded tubules. Addition of $0.5 \mathrm{mM}$ cystine dimethyl ester resulted in a decrease in intracellular proximal convoluted tubule ATP concentration. Incubation of proximal convoluted tubules with exogenous ATP restored intracellular ATP to near control levels. Moreover, in proximal convoluted tubules perfused in vitro, $1 \mathrm{mM}$ lumen and bath ATP significantly ameliorated the transport defect due to cystine loading. In contrast, cystine dimethyl ester had no significant effect on NaK ATPase activity, although $\mathrm{Mg}$ ATPase activity decreased by $24 \%$. These data demonstrate that cellular cystine loading inhibits transport by decreasing intracellular ATP and that exogenous ATP repletes intracellular ATP and ameliorates the transport defect in this model of the Fanconi syndrome of cystinosis.

There is now substantial evidence that incubation of renal tubules with exogenous nucleotides in vitro can affect the intracellular nucleotide pool (22-25). Incubation of oxygenated rabbit renal tubules for $90 \mathrm{~min}$ with either $250 \mu \mathrm{M}$ exogenous ATP, ADP, or AMP resulted in a two- to threefold increase in intracellular ATP concentration (22). A three- to fourfold increase in intracellular ATP was measured in oxygenated rabbit proximal tubule suspensions incubated for $1 \mathrm{~h}$ with $200 \mu \mathrm{M}$ of either ATP, ADP, or AMP (23). Both studies found that exogenous adenosine, inosine, and hypoxanthine were less effective at increasing intracellular ATP concentrations $(22,23)$. In this study, incubation of proximal convoluted tubules for $15 \mathrm{~min}$ with exogenous ATP resulted in a $40 \%$ increase in ATP concentration. More importantly, incubation of cystine-loaded proximal convoluted tubules with exogenous ATP resulted in repletion of intracellular ATP to near control levels.

It is not certain how exogenous adenine nucleotides result in an increase in intracellular ATP. Cellular uptake of extracel- lular ATP has been proposed (26-28), however, recent studies in proximal convoluted tubule suspensions are not consistent with this mechanism $(23,24)$. Exogenous ATP is rapidly degraded in tubular suspensions $(22-24,29)$. ATP, as well as ADP and AMP, increase intracellular $\operatorname{ATP}(22,23)$. Adenosine kinase inhibition with 5-iodotubercidin prevents the increase in cellular ATP by exogenous ATP (24). This is consistent with ATP not being directly transported into proximal tubule cells. There is increasing evidence that adenosine is the predominant transported species $(23,24,30)$. Addition of exogenous adenosine deaminase, which catalyzes the conversion of adenosine to inosine, prevents the ATP-induced increase in ATP concentration in proximal convoluted tubules (23). The greater ability of exogenous ATP to increase intracellular ATP in comparison with adenosine may be due to inhibition of adenosine kinase by high cellular concentrations of adenosine (24).

While there is an increase in intracellular ATP concentration in tubules incubated with exogenous nucleotides, they do not appear to substantially affect oxygenated tubules in vitro or in vivo $(22,31)$. Basal respiratory rates and CCCLP-uncoupled rates were not affected by exogenous ATP in a tubule suspension (22). Infusion of exogenous ATP- $\mathrm{MgCl}$ in normal rats in vivo had no affect on intracellular ATP concentration using ${ }^{31} \mathrm{P}$-nuclear magnetic resonance in vivo, and had no effect on proximal tubule respiration when studied in vitro (31). In this study we found that addition of exogenous ATP to tubules perfused in vitro resulted in a small increase in volume absorption when examined on a paired basis. However, the rate of volume absorption in tubules with lumen and bath ATP was $0.85 \pm 0.05 \mathrm{nl} / \mathrm{mm} \cdot \min (n=17)$, which was not significantly different than the $0.75 \pm 0.07 \mathrm{nl} / \mathrm{mm} \cdot \min (n=19)$ without exogenous ATP $(P=0.26)$. Furthermore, proximal convoluted tubules can be perfused under the conditions used in this study for several hours without a decrease in transport rates, suggesting that ATP production is not rate limiting under normal conditions (19).

This study demonstrated that cystine loading for $15 \mathrm{~min}$ reduces proximal convoluted tubule intracellular ATP concentrations by $59 \%$. This is comparable to the $63 \%$ reduction in cellular ATP measured after $10 \mathrm{~min}$ of anoxia (23). In addition, we examined the effect of exogenous ATP on the inhibition in proximal convoluted tubule volume absorption seen with cellular cystine loading. There was no significant difference in the control rate of volume absorption before addition of cystine dimethyl ester between the two groups. However, tubules without exogenous ATP had an $89 \%$ reduction in transport compared with the $45 \%$ seen with $1 \mathrm{mM}$ lumen and bath ATP $(P$ $<0.01)$. These data directly demonstrate that exogenous ATP 
can ameliorate the inhibition of proximal tubule transport when cellular ATP is depleted.

Alterations in renal metabolism have been demonstrated in other causes of the Fanconi syndrome (32). In maleic acid nephropathy, oxidation of most Krebs cycle intermediates is inhibited (33) and renal cortical ATP content is reduced (34). In patients with hereditary fructose intolerance, there is a deficiency of fructose-1-phosphate aldolase preventing further metabolism of fructose-1-phosphate. These patients develop the Fanconi syndrome upon consumption of fructose (35). Similarly, administration of high doses of fructose in rats results in an increase of fructose-1-P, proximal tubular dysfunction, and a decrease in proximal tubule ATP concentration (36). Interestingly, the decrease in renal cortical ATP content is attenuated by both exogenous phosphate and adenosine (37).

In this study, $V_{\max }$ NaK ATPase activity was not affected by cellular cystine loading. Interestingly, ouabain-insensitive $\left(\mathrm{Mg}^{++}\right.$ATPase) activity was significantly lower in cystine loaded tubules. $\mathrm{Mg}^{++}$ATPase activity measured under these assay conditions is a composite of several energy-consuming transport ATPases and general degradative phosphatase reactions. We considered two specific ATPase reactions in the first category, namely mitochondrial $F_{0} F_{1} \mathrm{H}^{+}$ATPase activity (oligomycin-sensitive) and plasma membrane $\mathrm{H}^{+}$ATPase activity (NEM-sensitive, vanadate- and oligomycin-insensitive). Since oligomycin, NEM, and vanadate were without effect on the difference in $\mathrm{Mg}^{++}$ATPase activity with and without cystine dimethyl ester, the cystine dimethyl ester-inhibitable phosphatase does not appear to be either mitochondrial or plasma membrane $\mathrm{H}^{+}$ATPase. Furthermore, the presence of EDTA in the mix and the vanadate insensitivity of the cystine dimethyl ester-responsive phosphatase argues against a $\mathrm{Ca}^{++}$ATPase activity as the target of cystine dimethyl ester. The enzyme may more likely represent a degradative ecto-ATPase activity or a relatively non-specific reaction, such as alkaline phosphatase. Whether or not a cystine dimethyl ester-mediated inhibition of such degradative processes could directly participate in the overall transport defect seen in this model remains to be seen.

The inhibition in transport due to cellular cystine loading could be due to several factors. Inhibition of proximal tubular transport can result from an inhibition in active transport or to an increased rate of back diffusion of transported solutes into the tubular lumen. Our previous data demonstrated that cystine dimethyl ester had no effect on the permeability of the proximal tubule to mannitol and bicarbonate (14). Thus, the inhibition is entirely due to an inhibition in active transport. Cellular cystine loading could potentially inhibit active transport by directly affecting the transporters responsible for solute transport on the apical or basolateral membrane or by inhibiting ATP production. This study examined the importance of ATP and the NaK ATPase activity in the transport defect in cystine-loaded proximal convoluted tubules. Cellular cystine loading results in a decrease in intracellular ATP concentration but had no affect on NaK ATPase activity measured under $V_{\max }$ conditions. The inhibition of transport is ameliorated by exogenous ATP. These data suggest that the inhibition in proximal tubule transport in cystine loaded tubules is largely the result of intracellular ATP depletion.

\section{Acknowledgments}

We are grateful for the technical assistance of Rebecca Archita and Ebtisam Shawky, and the able secretarial assistance of Janell McQuinn.
This work is supported by National Institutes of Health grants R29DK-38465-01 and DK41612-01, and American Heart Association grant 890664 (to Dr. Baum), and National Institutes of Health grant AM-21576 (to Dr. Marver).

The assertions contained herein are the private views of the authors and are not to be construed as official or as reflecting the views of the Department of the Navy or the Department of Defense.

\section{References}

1. Gahl, W. A., M. Renlund, and J. G. Thoene. 1989. Lysosomal transport disorders: cystinosis and sialic acid storage disorders. In The Metabolic Basis of Inherited Disease. C. R. Scriver, A. L. Beaudet, W. S. Sly, and D. Valle, editors. 6th ed. McGraw-Hill Inc., New York. 2619-2647.

2. Schneider, J. A., K. Bradley, and J. E. Seegmiller. 1967. Increased cystine in leukocytes from individuals homozygous and heterozygous for cystinosis. Science (Wash. DC). 157:1321-1322.

3. Schneider, J. A., F. M. Rosenbloom, K. H. Bradley, and J. E. Seegmiller. 1967. Increased free-cystine content of fibroblasts cultured from patients with cystinosis. Biochem. Biophys. Res. Commun. 29:527-531.

4. Patrick, A. D., and B. D. Lake. 1968. Cystinosis: electron microscopic evidence of lysosomal storage of cystine in lymph node. J. Clin. Pathol. 21:571575.

5. Schulman, J. D., K. H. Bradley, and J. E. Seegmiller. 1969. Cystine: compartmentalization within lysosomes in cystinotic leukocytes. Science (Wash. DC) 166:1152-1154.

6. Schulman, J. D., and K. H. Bradley. 1970. The metabolism of amino acids, peptides, and disulfides in lysosomes of fibroblasts cultured from normal individuals and those with cystinosis. J. Exp. Med. 132:1090-1104.

7. Gahl, W. A., N. Bashan, F. Tietze, I. Bernardini, and J. D. Schulman. 1982. Cystine transport is defective in isolated leukocyte lysosomes from patients with cystinosis. Science (Wash. DC) 217:1263-1265.

8. Steinherz, R., F. Tietze, W. A. Gahl, T. J. Triche, H. Chiang, A. Modesti, and J. D. Schulman. 1982. Cystine accumulation and clearance by normal and cystinotic leukocytes exposed to cystine dimethyl ester. Proc. Natl. Acad. Sci. USA. 79:4446-4450.

9. Gahl, W. A., F. Tietze, N. Bashan, R. Steinherz, and J. D. Schulman. 1982. Defective cystine exodus from isolated lysosome-rich fractions of cystinotic leucocytes. J. Biol. Chem. 257:9570-9575.

10. Gahl, W. A., F. Tietze, N. Bashan, I. Bernardini, D. Raiford, and J. D. Schulman. 1983. Characteristics of cystine counter-transport in normal and cystinotic lysosome-rich leucocyte granular fractions. Biochem. J. 216:393-400.

11. Goldman, R., and A. Kaplan. 1973. Rupture of rat liver lysosomes mediated by L-amino acid esters. Biochim. Biophys. Acta. 318:205-216.

12. Reeves, J. P. 1979. Accumulation of amino acids of lysosomes incubated with amino acid methyl esters. J. Biol. Chem. 254:8914-8921.

13. Foreman, J. W., M. A. Bowring, J. Lee, B. States, and S. Segal. 1987. Effect of cystine dimethylester on renal solute handling and isolated renal tubule transport in the rat: A new model of the Fanconi syndrome. Metabolism. 36:11851191.

14. Salmon, R. F., and M. Baum. 1990. Intracellular cystine loading inhibits transport in the rabbit proximal convoluted tubule. J. Clin. Invest. 85:340-344.

15. Uchida, S., and H. Endou. 1988. Substrate specificity to maintain cellular ATP along the mouse nephron. Am. J. Physiol. 255:F977-F983.

16. Lemasters, J. J., and C. R. Hackenbrock. 1978. Firefly luciferase assay for ATP production by mitochondria. In Methods in Enzymology. M. A. Deluca, editor. Academic Press, New York. 57:36-50.

17. O'Neil, R. G., and W. P. Dubinsky. 1984. Micromethodology for measuring ATPase activity in renal tubules: mineralocorticoid influence. Am. J. Physiol. 247:C314-C320.

18. Burg, M. B., J. Grantham, M. Abramow, and J. Orloff. 1966. Preparation and study of fragments of single rabbit nephrons. Am. J. Physiol. 210:1293-1298.

19. Baum, M. 1987. Insulin stimulates volume absorption in the rabbit proximal convoluted tubule. J. Clin. Invest. 79:1104-1109.

20. Gluck, S., S. Kelly, and Q. Al-Awgati. 1982. The proton translocating ATPase responsible for urinary acidification. J. Biol. Chem. 257:9230-9233.

21. Xie, X. S., and D. K. Stone. 1986. Isolation and reconstitution of the clathrin-coated vesicle proton translocating complex. J. Biol. Chem. 261:24922495.

22. Weinberg, J. M., and H. D. Humes. 1986. Increases of cell ATP produced by exogenous adenine nucleotides in isolated rabbit kidney tubules. Am. J. Physiol. 250:F720-F733.

23. Mandel, L. J., T. Takano, S. P. Soltoff, and S. Murdaugh. 1988. Mechanisms whereby exogenous adenine nucleotides improve rabbit renal proximal function during and after anoxia. J. Clin. Invest. 81:1255-1264.

24. Weinberg, J. M., J. A. Davis, A. Lawton, and M. Abarzua. 1988. Modulation of cell nucleotide levels of isolated kidney tubules. Am. J. Physiol. 254:F311F322. 
25. Coulson, R. 1976. Metabolism and excretion of exogenous adenosine $3^{\prime}: 5^{\prime}$-monophosphate and guanosine 3':5'-monophosphate. J. Biol. Chem. 254:4958-4967.

26. Chaudry, I. H. 1981. Does ATP cross the cell plasma membrane? Yale J. Biol. Med. 55:1-10.

27. Maxild, J. 1978. Effect of externally added ATP and related compounds on active transport of p-aminohippurate and metabolism in cortical slices of the rabbit kidney. Arch. Int. Physiol. Biochim. 86:509-530.

28. Pant, H. C., S. Terakawa, T. Yoshioka, I. Tasaki, and H. Gainer. 1979. Evidence for the utilization of extracellular $\left[\gamma-{ }^{32} \mathrm{P}\right]$ ATP for the phosphorylation of intracellular proteins in the squid giant axon. Biochim. Biophys. Acta 582:107114.

29. Saggerson, E. D., C. A. Carpenter, and J. A. S. Veiga. 1983. Stimulation of renal gluconeogenesis by exogenous adenine nucleotides. Biochim. Biophys Acta. 755:119-126.

30. Trimble, M. E., and R. Coulson. 1984. Adenosine transport in perfused rat kidney and renal cortical membrane vesicles. Am. J. Physiol. 246:F794-F803.

31. Stromski, M., K. Gaudio, G. Thulin, and N. Siegel. 1987. Exogenous ATP does not augment ATP levels or metabolic function in vivo. Kid. Intern. 31:402a. (Abstr.)

32. DuBose, T. D., Jr., and R. J. Alpern. 1989. Membrane Transport systems. In The Metabolic Basis of Inherited Disease. C. R. Scriver, A. L. Beaudet, W. S. Sly, and D. Valle, editors. 6th ed. McGraw-Hill Inc., New York. 2539-2568.

33. Angielski, S., and J. Rogulski. 1962. Effect of maleic acid on the kidney. Acta Biochim. Polon. 9:357-364.

34. Kramer, H. J., and H. C. Gonick. 1970. Experimental Fanconi syndrome. J. Lab. Clin. Med. 11:799-808.

35. Morris, R. C., Jr. 1968. An experimental renal acidification defect in patients with hereditary fructose intolerance. J. Clin. Invest. 47:1389-1398.

36. Burch, H. B., S. Choi, C. N. Dence, T. R. Alvey, B. R. Cole, and O. H. Lowry. 1980. Metabolic effects of large fructose loads in different parts of the rat nephron. J. Biol. Chem. 255:8239-8244.

37. Morris, R. C., Jr., K. Nigon, and E. B. Reed. 1978. Evidence that the severity of depletion of inorganic phosphate determines the severity of the disturbance of adenine nucleotide metabolism in the liver and renal cortex of the fructose-loaded rat. J. Clin. Invest. 61:209-220. 